
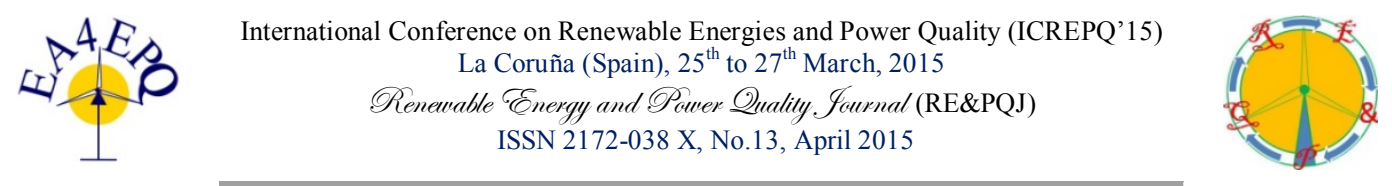

\title{
Contribution of the Losses in the Conductors of an Installation in the Use of Electronic Ballasts in Fluorescent Illumination
}

\author{
J.A. Lobão ${ }^{1}$, T. Devezas ${ }^{2}$ and J.P.S. Catalão $0^{2,3,4}$ \\ ${ }^{1}$ Polytechnic of Guarda \\ Av. Dr. Francisco Sá Carneiro 50, 6300-559 Guarda (Portugal) \\ Phone: +351271220 111, Fax: +351271220690 \\ e-mail: jlobao@ipg.pt \\ ${ }^{2}$ University of Beira Interior \\ R. Fonte do Lameiro, 6200-001 Covilhã (Portugal) \\ Phone: +351 275329 914, Fax: +351 275329972 \\ e-mail: tessalen@ubi.pt; catalao@ubi.pt \\ ${ }^{3}$ INESC-ID, R. Alves Redol, 9, 1000-029 Lisbon, Portugal \\ ${ }^{4}$ IST, University of Lisbon, Av. Rovisco Pais, 1, 1049-001 Lisbon, Portugal
}

\begin{abstract}
The global economic and energy situation implies that all contributions for reducing energy consumption are important and relevant in terms of study and investment analysis. In electrical installations, energy consumption can be reduced by reducing losses in the conductors, associated with the use of electronic ballasts in fluorescent illumination, allowing a better use of the energy and of the installed power, which can be an important issue, particularly when using renewable energies. In this sense, this study presents a new software application that compares and chooses the best investment in the acquisition and installation of electronic ballasts in fluorescent illumination.
\end{abstract}

\section{Key words}

Electronic ballasts, decision support, sustainable energy, fluorescent illumination, losses

\section{Introduction}

Energy demand forecast for the Organization for Economic Cooperation and Development (OECD) has little growth and, in 2035 is less than half of demand from countries not members of the OECD. However the global energy demand is great. In Fig. 1 it can be seen the demand for primary energy and Fig. 2 the share (in percent) of global growth from 2012 to 2035. Power consumption will increase in the coming years in any scenario as regards the US Energy Information Administration in its Annual Energy Outlook 2014[1], Fig. 3
Primary energy demand, 2035 (Mtoe)

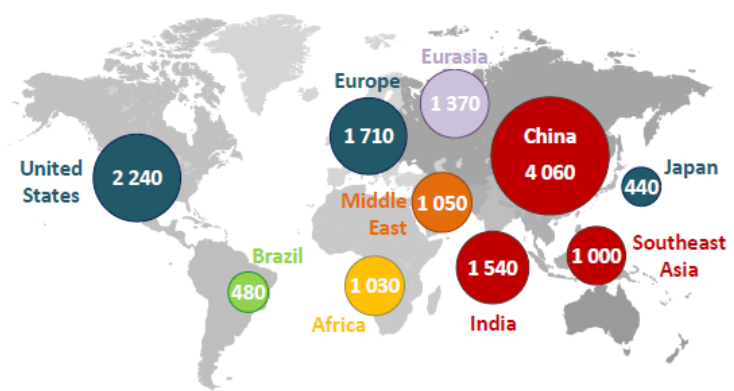

Fig. 1- Primary energy demand in 2035 in Mtoe ([2]).

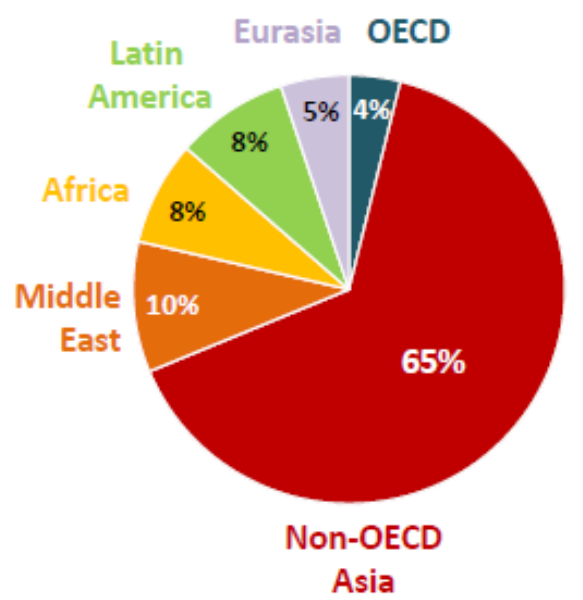

Fig. 2- \% Overall growth from 2012 to 2035 ([2]). 


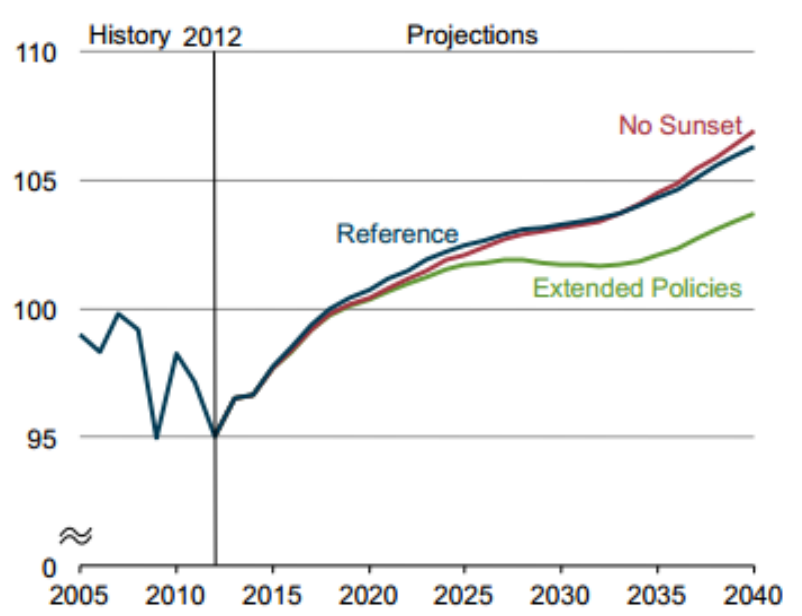

Fig.3. Total energy consumption in three cases, 2005-40 (quadrillion Btu) ([1]).

All data point in the same direction: the power consumption will increase, particularly due to increased consumption by economies of emerging countries, and the offer will suffer some major changes due to technological developments which enable new sources so far not considered conventional and increased energy production from RES (Renewable Energy Sources), as can be seen in the Figs. 4 and 5.

\section{Primary energy production}

\section{Billion toe}

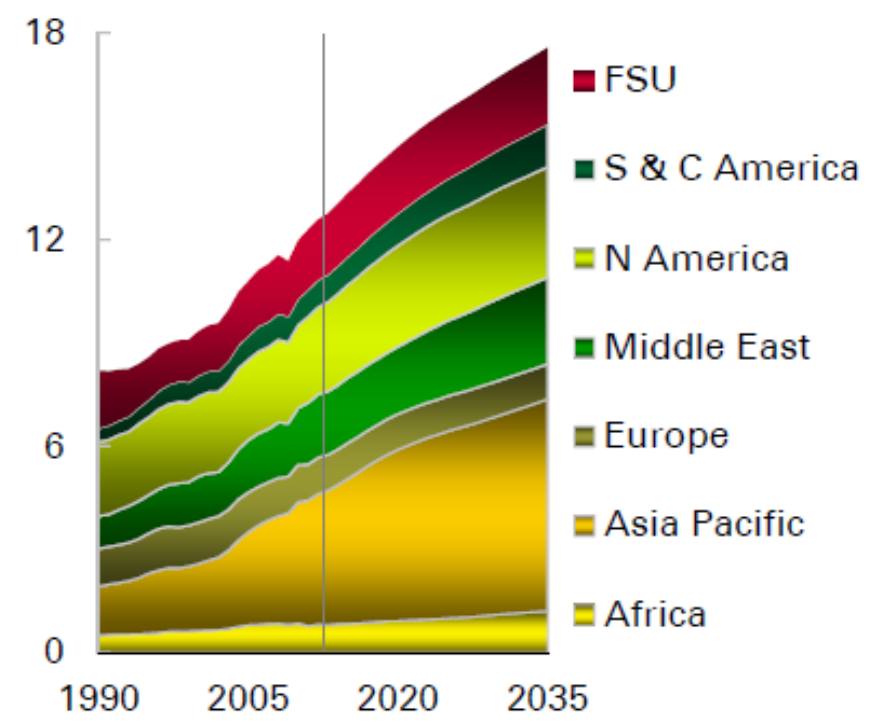

Fig. 4- World production of primary energy ([3]).

\section{New energy forms}

\section{Billion toe}

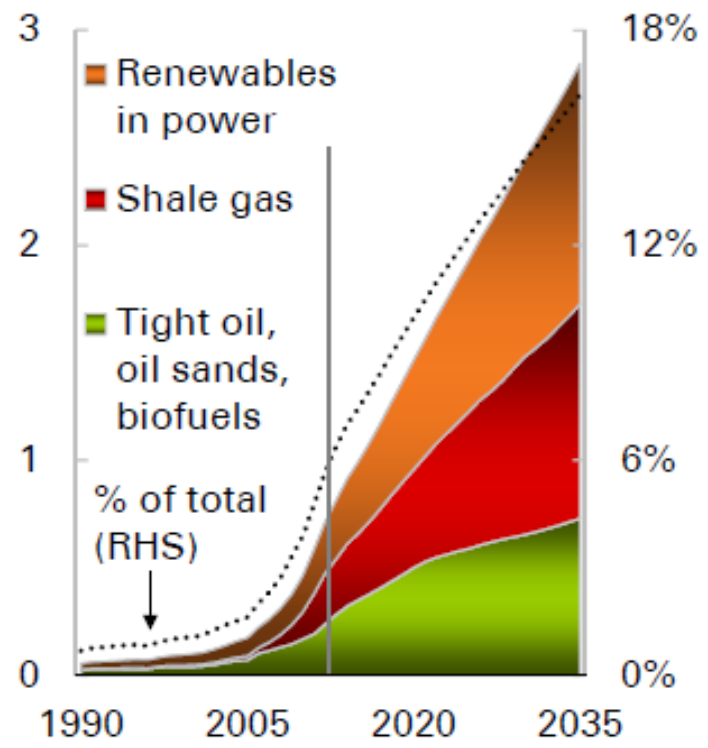

Fig. 5. World primary energy production by new forms of energy ([3]).

The implementation of energy efficiency measures in all sectors of activity has been a constant, but two-thirds of the economic potential to improve energy efficiency remains untapped in the period to 2035 (IEA WEO 2012[2]), Fig. 6.
N Unrealised energy efficiency potential
- Realised energy efficiency potential

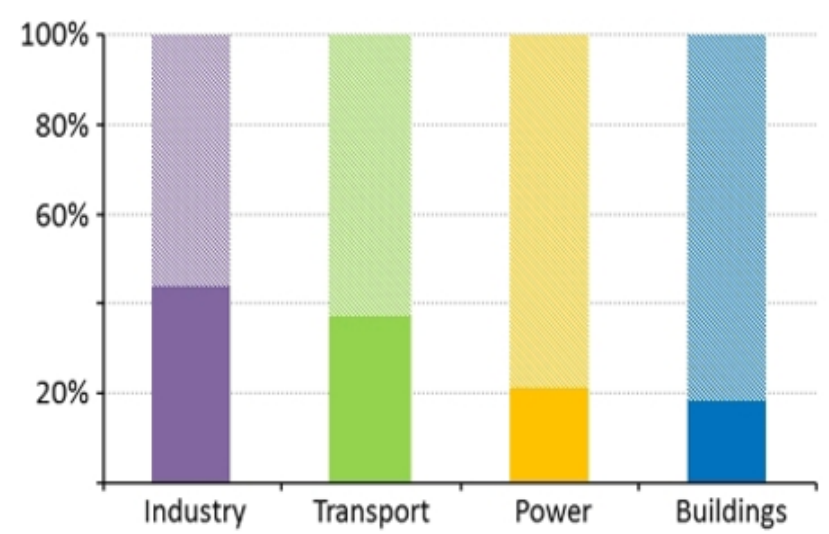

Fig. 6. Economic potential to improve energy efficiency untapped in the period to 2035 ([2]). 
In this sense, this study presents a new software application that compares and chooses the best investment in the acquisition and installation of electronic ballasts in fluorescent illumination. The electronic ballasts choice focuses on the following factors: cost, power consumption, reduction of losses in the conductors, useful life and interest rate. The losses in the conductors will be analysed based on the current which passes throughout the electrical installation. It is also possible to determine the $\mathrm{CO}_{2}$ emissions reduction corresponding to the power consumption reduction.

\section{Development}

\section{A. Identification of the Parameters \\ Physical parameters:}

Distribution boxes $\left(\mathrm{Q}_{\mathrm{k}}\right)$;

Connections between distribution boxes;

Length of output $\mathrm{t}_{\mathrm{i}}$ conductors in distribution boxes;

Section of outputs conductors in distribution boxes;

\section{Load parameters:}

Power of the loads connected to the electrical installation; Efficiency of the loads; Power factor of the loads;

Daily load diagram with conventional ballast (figure 8); Daily load diagram with electronic ballast (figure 9).

\section{Operating parameters:}

Operating time of the electrical installation; Monthly operating days (d); Months of annual operation (m); Cost of electricity $(€)$

\section{B. Installation Characteristics}

Fig. 7 shows a typical installation with the respective parameters.

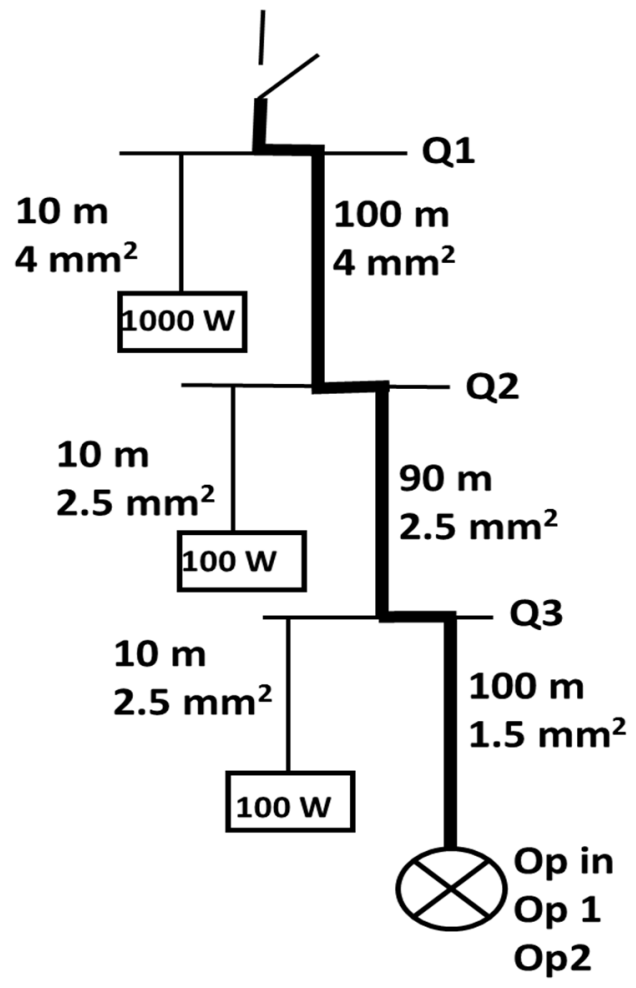

Fig. 7. Scheme of an installation.
Fig. 8 represents an industrial lamp with conventional ballast, applied op in, and their respective values $(85 \mathrm{~W}$ and power factor 0.98 ).

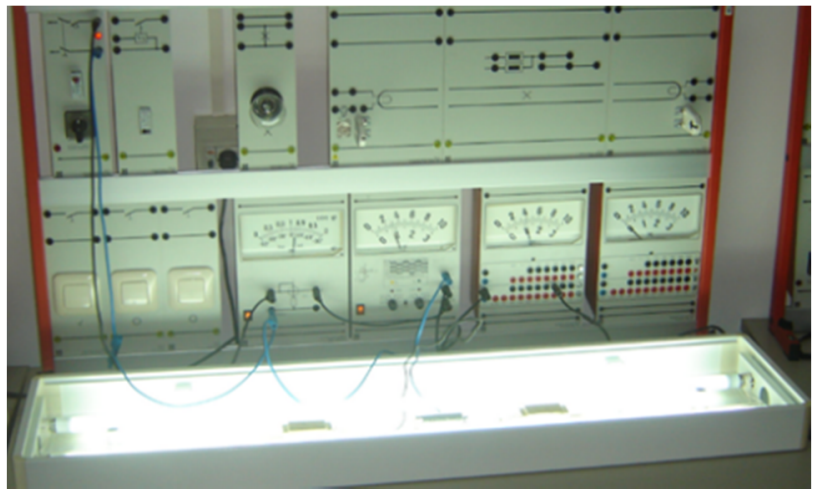

Fig. 8. Industrial equipment with conventional ballast.

Fig. 9 represents an industrial lamp with electronic ballast, applied op 2, and their respective values $(70 \mathrm{~W}$ and power factor 1$)$.

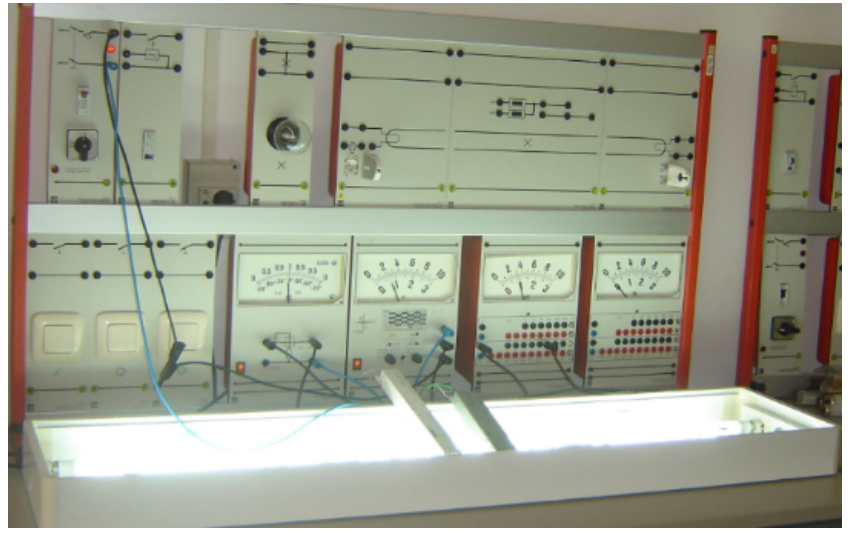

Fig. 9. Industrial equipment with electronic ballast.

\section{Calculations}

After inputting the parameters and load diagrams, the following calculations are made:

- Determination of the load diagram associated to the output distribution boxes, adding the corresponding load diagrams [4].

- Difference in cable losses (G1) in the conductors affected by the changed equipment (identified in bold in Fig.7) is calculated using the Joule's law.

$\mathrm{G} 1=\sum_{\mathrm{j}=1}^{\mathrm{n}}\left\{\left[\mathrm{R}[\mathrm{k}, \mathrm{i}]\left(\mathrm{I}[\mathrm{k}, \mathrm{i}]_{1}\right)^{2}-\mathrm{R}[\mathrm{k}, \mathrm{i}]\left(\mathrm{I}[\mathrm{k}, \mathrm{i}]_{2}\right)^{2}\right] t_{j} €_{j}\right\}_{\mathrm{j}} \mathrm{dm}$

- Profits from the variation of power equipment (G2).

$\mathrm{G} 2=\sum_{\mathrm{j}=1}^{\mathrm{n}}\left\{\left[\left(P_{1}[\mathrm{k}, \mathrm{i}]-P_{2}[\mathrm{k}, \mathrm{i}]\right)\right] t_{j} €_{j}\right\}_{\mathrm{j}} \mathrm{dm}$ 
- Total profits.

$$
\mathrm{Rec}=\mathrm{G} 1+\mathrm{G} 2
$$

- For the Economic Evaluation the VAL (present net value) or Payback Period (PP) [5], is used, which is computed from the sum of the annual cash-flows (Rec) for a given annual interest rate (a).

$$
\mathrm{VAL}=\sum_{j=1}^{m} \frac{\operatorname{Rec}_{j}}{(1+a)^{j}}-\sum_{j=0}^{m-1} \frac{I_{j}}{(1+a)^{j}}
$$

\section{Results}

Fig. 10 presents the results of the new software application to the scheme of Fig. 7. The results compare an initial situation of a conventional ballast, Fig. 8, and an electronic one, Fig. 9.

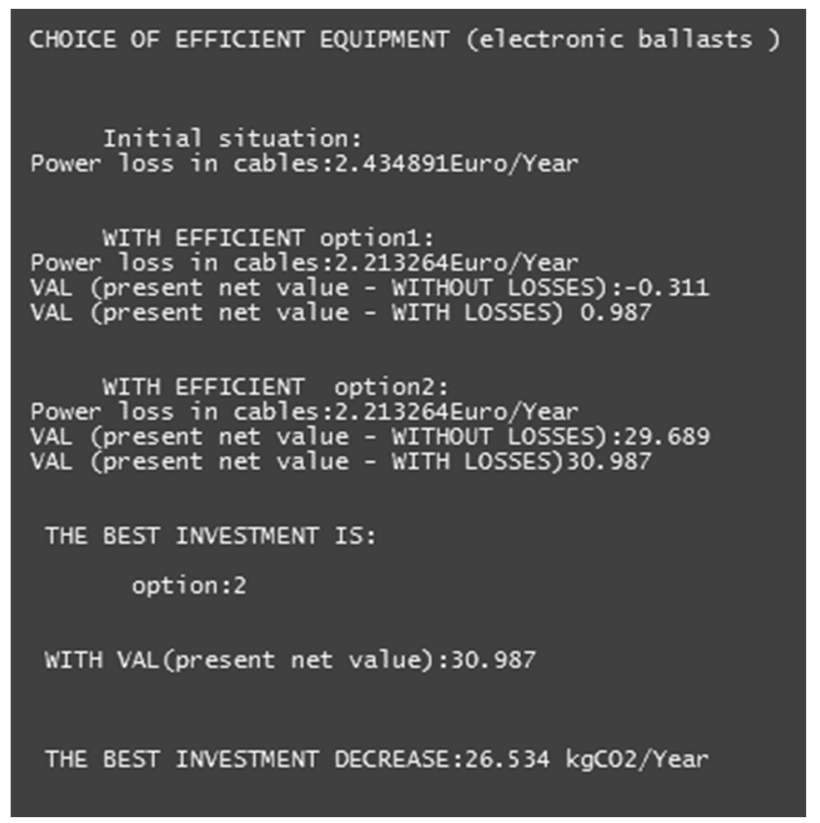

Fig. 10. Results.

\section{Conclusions}

The application developed in this paper was intended to demonstrate that the losses caused by the electronic ballast in the conductor's influences their choice. These losses in electrical installations, although small, are not null and can make a considerable difference in the economic evaluation supporting the investment decision. So, we contributed to the efficiency measures implemented, allowing a better use of the energy and of the installed power, which can be an important issue, particularly when using renewable energies.

\section{Acknowledgments}

This work was supported by FEDER funds (European Union) through COMPETE and by Portuguese funds through FCT, under Projects FCOMP-01-0124-FEDER$020282 \quad$ (Ref. PTDC/EEA-EEL/118519/2010), UID/CEC/50021/2013 and PEst-OE/EGE/UI4056/2014 UDI/IPG. Also, the research leading to these results has received funding from the EU Seventh Framework Programme FP7/2007-2013 under grant agreement no. 309048.

\section{References}

[1] U.S. Energy information administration, Annual energy outlook 2014

[2] International Energy Agency. World energy outlook 2012;

[3] BP. Energy Outlook 2035; 2014

[4] J.A. Lobão, T. Devezas, J.P.S. Catalão, "Influence of cable losses on the economic analysis of efficient and sustainable electrical equipment", Energy, Vol. 65, pp. 145-151, 2014;

[5] Miomir K."Technical and economic analysis of road lighting solutions based on mesopic vision", Building and Environment; Vol. 44, pp 66-75, 2009. 